\title{
LA POLÍ́TICA EN LA CONSTELACIÓN POSTNACIONAL. UNA APROXIMACIÓN A LA CONCEPCIÓN HABERMASIANA DEL ESTADO ${ }^{1 *}$
}

\author{
JUAN CARLOS VELASCO \\ Instituto de Filosofía del CSIC (Madrid)
}

\begin{abstract}
RESUMEN: La imparable pérdida del poder soberano de los Estados nacionales y el correlativo afloramiento de una constelación postnacional serían dos de las grandes tendencias que, según Habermas, caracterizarían en términos políticos el actual estado de cosas en el mundo. Ante este contexto geopolítico emergente, cuyos lineamientos definitivos aún estarían por definir, Habermas perfila una posible respuesta política en clave democrática: recuperar el proyecto cosmopolita de Kant y avanzar en la juridificación de la esfera internacional. En ese horizonte, compatibilizar la necesidad de una gobernanza global de los asuntos comunes de la humanidad y las exigencias de participación democrática constituye uno de los mayores escollos a salvar. La conformación de una praxis democrática postwestfaliana en concordancia con una estructuración multinivel de las relaciones internacionales podría representar una salida plausible.
\end{abstract}

PALABRAS CLAVE: Habermas, Estado nacional, constelación postnacional, cosmopolitismo, gobernanza global.

\section{Politics in the Postnational Constellation. An Approach to Habermas's Conception of the State}

\begin{abstract}
The steady loss of sovereign power of the national states and the correlative transition to a post-national constellation are, according to Habermas, among the major trends that characterize the current state of affairs in the world in political terms. Against this geopolitical background in which clear guidelines remain to be defined, Habermas outlines a possible political response with a democratic design: he suggests to recover the cosmopolitan project of Kant and to expedite the constitutionalization of the international sphere. One of the biggest challenges in this regard consists in reconciling the need for global governance of common affairs of humanity with demands for democratic participation. The configuration of a post-westphalian democratic practice in accordance with a multi-level structure of international relations could be a plausible solution.
\end{abstract}

KEY WORDS: Habermas, national State, postnational constellation, cosmopolitanism, global governance.

El cuestionamiento del Estado nacional y la revitalización del ideal cosmopolita van de la mano en la era de la globalización. Una larga serie de destacados filósofos y teóricos sociales contemporáneos han subrayado la entidad de este nexo y han argumentado a favor de diversas formas de gobernanza global. Entre esos autores, Jürgen Habermas aparece como una de las figuras más señeras. Sin embargo, no todo su pensamiento político puede

1 "Este artículo se ha elaborado en el marco de un proyecto de investigación financiado por el Ministerio de Economía y Competitividad: «Derechos humanos y justicia global en el contexto de las migraciones internacionales» (FFI2013-42521-P). 
ser tildado de cosmopolita. La existencia de ciertos giros o incluso cesuras no tiene nada de particular en una obra como la de Habermas, en la que, dada su confesa vocación de convertirse en autoconciencia crítica del momento histórico, la definición de su contenido en absoluto es ajena a los diversos avatares de la filosofía y las ciencias sociales ni a los profundos cambios registrados en el contexto socio-político. De ahí también que, junto a las sustanciales continuidades detectables en la trayectoria intelectual habermasiana, signo de su coherencia interna, también sean reconocibles múltiples modificaciones y rectificaciones. Muy probablemente uno de los cambios de acento más significativos se localice en el terreno de su filosofía política y consistiría en el desplazamiento desde una compresión estadocéntrica de la política a un enfoque que cabría calificar de globalista: nuestro autor pasó de ocuparse de los problemas de legitimidad y calidad democrática que aquejaban al Estado contemporáneo y, por tanto, a dar por sentado que ése era el marco «natural» de la acción política, a entender que sin una visión global y, por ende, supraestatal, no es posible afrontar los problemas políticos fundamentales de nuestro mundo.

Si hubiera que datar el momento en que tuvo lugar ese viraje globalista en los planteamientos filosófico-políticos de Habermas, habría que señalar el año 1995, fecha en que se conmemoró el segundo centenario del famoso opúsculo de Kant Sobre la paz perpetua ${ }^{2}$. A partir del artículo que Habermas escribió para la ocasión, en sus textos se registra una mutación notoria que afecta, en primer lugar, a la elección de temas, pero que acaba reflejándose en sus orientaciones políticas fundamentales ${ }^{3}$. Desde entonces, la inmensa mayoría de sus reflexiones sobre materia política versan de manera casi exclusiva sobre la esfera transnacional y supranacional y mantienen una relación estrecha con el curso de los acontecimientos en ese mismo espacio. Aunque las cuestiones que traspasan las fronteras territoriales de cada uno de los Estados no estaban completamente ausentes en los escritos del período anterior, no eran ciertamente las que determinaban el enfoque básico desde el que se abordaba el conjunto de la problemática filosófico-política. Esta significativa ampliación del objeto de su filosofía política no es tan sólo una acomodación a los profundos cambios geopolíticos de los que hemos

2 El artículo lleva por título «La idea kantiana de la paz perpetua. Desde la distancia histórica de 200 años» (HABERMAs, 1999, pp. 147-188). Para una contextualización de las coordenadas histórico-conceptuales de este primer texto de inspiración kantiana, véase Velasco, 1997. Años después, en 2004, Habermas presenta una versión mucho más sofisticada y prolija del programa cosmopolita kantiano con el objeto adaptarlo al nuevo orden mundial surgido a partir del 11 de septiembre: «El proyecto kantiano y el Occidente escindido» (Habermas, 2006a). Para desarrollos posteriores de la misma idea, véanse Habermas, 2006c, 2009 y 2012.

3 En 1992, apenas tres años antes de que apareciera su primer artículo sobre el cosmopolitismo kantiano, Habermas publicó su opus magnum sobre la filosofía del derecho y del Estado democrático (cfr. HABERMAS, 1998). El enfoque de esta obra está tan circunscrito a los límites de cada uno de los Estados que no dedica ni siquiera una breve sección al derecho internacional. 
sido testigos en los últimos años (algunos de los cuales, especialmente durante los años noventa, dieron alas a un pasajero optimismo cosmopolita ${ }^{4}$, del que nuestro autor a duras penas logró sustraerse), sino que su explicación cabal ha de entenderse en continuidad con la decidida orientación normativa universalista que caracteriza toda su filosofía práctica. Más que una ruptura, se trata de una consumación de sus propios planteamientos. El asunto principal de este artículo no será otro que el de dar cuenta de tales mutaciones.

En la primera parte de este trabajo se plantea la cuestión de si, desde las coordenadas habermasianas, el Estado territorial moderno constituye la forma política idónea para afrontar la diversidad y complejidad de los desafíos a los que se enfrentan las sociedades contemporáneas ${ }^{5}$. Su respuesta consistirá básicamente en señalar que, en un mundo en el que los conflictos y los riesgos están cada vez más globalizados, y en el que también las decisiones y las posibles soluciones deben ser adoptadas en una escala igualmente global, el Estado territorial soberano no parece ser la herramienta más adecuada (1). Si se responde así no puede uno dejar de preguntarse por la forma de organización política de la que tendría que dotarse un mundo globalizado y por la misión que se reservaría al Estado tradicional en ese nuevo horizonte global: ésa es precisamente la materia de la segunda sección del artículo (2). En la tercera y última parte se presenta una fórmula tentativa que, con el fin de paliar el notorio desacoplamiento existente a nivel global entre una integración económica fuerte y una integración política débil, trata de conciliar una forma de gobernanza global con las exigencias de una noción robusta de democracia (3).

4 El colapso del bloque soviético entre 1989-1991 dio lugar a una nueva configuración geopolítica que dejaba atrás un mundo bipolar y permitía abrigar la esperanza de que de sus ruinas emergiera un nuevo mundo en el que la humanidad entera viviría unida. Esa ilusión de un mundo tendencialmente unificado en términos políticos —un escenario que guardaría estrecha correspondencia con el final de la historia, por emplear una expresión profusamente divulgada en aquellos años por Francis Fukuyama, que no hacía sino rehabilitar el añejo lenguaje hegeliano- resultó acaso plausible únicamente durante un breve período de tiempo, pues a partir de los atentados del 11-S se hizo evidente que el estado de guerra nunca había abandonado a este mundo y que éste no era sino constitutivamente multipolar. Al respecto, véanse KervÉgan, 2013, pp. 174 y 177; y García PAScual, 2015, pp. 151-155. Sea como fuera, y como afirma Iglesia Vila (2011, p. 1151), «el tercer milenio empezó con una euforia humanista», y prueba de ello sería la Cumbre del Milenio de septiembre de 2000 y el compromiso de 189 Estados con los llamados Objetivos de Desarrollo del Milenio. Este optimismo se truncaría, sin embargo, a partir de 2011 cuando la seguridad pasó a ser el tema central de la agenda internacional.

5 Habermas no formula abiertamente la cuestión de la definición del marco en el que ha afrontarse cada desafío o dirimirse cada contencioso político, aunque ofrezca argumentos para afrontarlos con rigor. No obstante, desde planteamientos afines a los de Habermas se ha presentado expresamente esta cuestión como un problema de escala, cfr. FrasER, 2008. 


\section{LA MERMa DE LA SOBERANÍA ESTATAL Y EL ADVENIMIENTO DE LA CONSTELACiÓN POSTNACIONAL}

El Estado nacional moderno - el Estado territorial soberano- representa, según Habermas, una destacada etapa intermedia en el proceso histórico de plasmación o realización práctica de las exigencias de una moral universalista fundada en los presupuestos de la acción comunicativa, exigencias que en el ámbito político se convierten en requerimientos de autogobierno democrático. Aunque Habermas subraya que esa forma de Estado no es una entidad democrática per se, constata que «siempre que se han dado democracias de corte occidental éstas han adoptado la forma de un Estado-nación» ${ }^{6}$. El reconocimiento de un cierto vínculo histórico entre democracia y Estado nacional no es impedimento sin embargo para señalar la ambigüedad constitutiva de un Estado comprometido con la suerte de una nación: «La nación tiene dos caras [...]. En las categorías del Estado nacional se encuentra incrustada la tensión entre el universalismo de una comunidad jurídica igualitaria y el particularismo de una comunidad con un destino histórico» ${ }^{7}$. Existe un nexo interno y conceptual entre Estado de derecho y democracia ${ }^{8}$, pero no uno entre Estado nacional y democracia que vaya más allá de una relación meramente contingente. En cualquier caso, lo más relevante de esta aproximación a la noción de Estado sería su carácter eminentemente normativo y su vinculación directa con la prioridad otorgada a la democracia en la filosofía política de Habermas. Si hay un hilo que recorre toda su monumental obra es precisamente el ideal de democracia, a la que él mismo una vez llamó la palabra mágica de su pensamiento9.

De esa consideración relativamente amable del Estado nacional Habermas se ha ido alejando en el transcurso de las dos últimas décadas. Aunque el Estado nacional suponga un indudable progreso en la medida en que proporciona un marco para el ejercicio de la participación y la solidaridad de los ciudadanos, el pensador germano se ha ido convenciendo de que tiene que ser rebasado por nuevas formas de organización política de alcance más inclusivo. El

6 Habermas, 2000, p. 86.

7 Habermas, 1999, p. 91. Fruto precisamente del empeño por liberar la concepción del Estado de adherencias particularistas (de honda raigambre romántica) sería el planteamiento postnacional de la política que Habermas hizo suyo a partir de los años ochenta, cfr. Habermas, 1989. Su defensa del patriotismo constitucional también ha de verse como expresión distinguida de ese mismo esfuezo. Sobre el sentido y contexto de esta última noción, cfr. VELASCO, 2001.

8 Cfr. Habermas, 1999, pp. 247-258.

9 La fijación de Habermas en la idea de democracia se retrotrae a su época de adolescente y al impacto que experimentó al conocer en su completo alcance la radical inhumanidad del régimen nazi. Desde los tiempos de la liberación del suelo alemán efectuada por las tropas aliadas (Habermas evita hablar en este contexto de ocupación), esa noción contiene para él connotaciones sumamente positivas: “Democracia” era para mí la palabra mágica, no el liberalismo anglosajón», afirma en un revelador texto sobre los orígenes biográficos de sus motivaciones políticas e intelectuales más arraigadas (HABERMAS, 2006b, p. 26). 
carácter territorial y poblacionalmente acotado de la acción política que se desarrolla en un Estado nacional es incongruente con el alcance universalista de los presupuestos inclusivos del principio discursivo, que prescribe que los efectos de las normas y decisiones colectivas sólo son legítimos si son aceptados sin coacción por todos los posibles afectados ${ }^{10}$. Y esto con frecuencia no es el caso en un mundo cada vez más densamente entretejido, pues las decisiones que los diversos Estados adoptan en su ámbito jurisdiccional tienen consecuencias allende sus fronteras y repercuten en la vida de los ciudadanos de otros Estados que no tienen la más mínima oportunidad de participar en la toma de decisiones ${ }^{11}$. Esta incongruencia territorial desmiente la identidad básica presupuesta en la idea misma de democracia: una identidad —al menos tendencial— entre quienes deciden y quienes son afectados por las decisiones tomadas. Sin embargo, hasta llegar a hacer suya esta valoración crítica en términos discursivos - y, por ende, universalistas - del papel del Estado, Habermas ha recorrido un largo sendero, algunos de cuyos hitos se señalarán a continuación.

En «Concepto de participación política» $(1958)^{12}$, uno de los primeros textos que Habermas dedica a la teoría política, su comprensión de la democracia se encuadra por completo en el marco nacional. Adopta ese mismo enfoque estatista en su primera gran obra, Historia y crítica de la opinión pública (1962), en donde trata de elucidar las bases participativas de la democracia y del Estado de derecho, que para él no son otras que la publicidad —en el sentido de una esfera pública política- y la discusión. Años más tarde, en uno de sus libros más celebrados, Problemas de legitimación del capitalismo tardío (1973), cuando analizó la crisis económica, que por aquel entonces afectaba a los países capitalistas, y, sobre todo, la crisis fiscal que aquejaba a los Estados de Bienestar, pronosticó que dichas crisis se desplazarían desde el subsistema económico hacia el subsistema político y se expresarían como crisis de legitimación. Daba por sentado que todas estas transformaciones tendrían lugar en el interior de las fronteras de cada Estado. Obviaba las interacciones con otros Estados y apenas prestaba atención a las estrechas relaciones de interdependencia existentes. En descargo de Habermas cabría alegar que no era ésta una rareza suya, sino que, en aquellos tiempos en que el nacionalismo metodológico campaba a sus anchas, era el modo habitual en que se formulaba cualquier cuestión política ${ }^{13}$.

10 Toda la filosofía práctica habermasiana — tanto en el ámbito ético como en el jurídico-político - gira en torno al denominado principio discursivo, conforme al cual «sólo son válidas aquellas normas a las que todos los posibles afectados puedan prestar su asentimiento como participantes en discursos racionales» (HABERMAS, 1998, p. 172). Como señala SEYLA BenhabiB (2005, p. 20), este principio tiene el carácter de «metanorma», en el sentido de que las «normas específicas que puedan considerarse válidas deben ser probadas a través de procedimientos que respondan a este criterio». Sobre el desarrollo de la ética discursiva, cfr. VELASCO, 2013, pp. 70-90.

11 Cfr. Habermas, 2000, p. 95.

12 Cfr. Habermas, 1973.

13 El «nacionalismo metodológico» no es una propuesta teórica expresamente definida, sino más bien un presupuesto tácito de la mayor parte de las teorías sociales. Bajo tal 
Sea como fuera, en los escritos de esa década también daba por sentado que el ámbito de aplicación del concepto de legitimidad eran los órdenes políticos de dominación, esto es, las instituciones básicas del Estado y de la sociedad o, dicho de manera más precisa, «las sociedades organizadas estatalmente». De manera explícita, dejaba fuera de ese ámbito tanto a las corporaciones multinacionales como al mercado mundial ${ }^{14}$.

Tres décadas después, cuando nuestro autor se puso a analizar la crisis que aún sigue golpeando a las sociedades occidentales, introdujo variables de distinto tenor, muchas de ellas de alcance supraestatal o transfronterizo. Empieza apuntando que en el período transcurrido entre la crisis de los primeros años setenta y la iniciada en 2007/2008 se pusieron en marcha por doquier políticas neoliberales de desregularización y se incrementó espectacularmente el grado de interdependencia de las economías nacionales, se multiplicaron las empresas multinacionales y se potenciaron los organismos financieros internacionales ${ }^{15}$. El cambio decisivo se produjo con el crecimiento de los mercados globales, pues entonces se rompió «el equilibrio en detrimento de la autonomía y el espacio de acción de los actores estatales en materia de política económica» ${ }^{16}$. Esa subordinación se hizo especialmente notoria frente a la banca: «la capacidad de actuación política de unos Estados nacionales que velan celosamente por su soberanía minada hace ya mucho tiempo no alcanza para sustraerse a los imperativos de un sector bancario sobredimensionado y disfuncional $»^{17}$. Todo ello conduce, entre otras cosas, a que ya no

etiqueta se entiende generalmente aquel enfoque epistémico que considera el Estado nacional como el modelo de organización política y social por antonomasia y, sobre todo, como el punto de partida incuestionable para el estudio de los procesos sociales, de modo que todos los análisis se han de ajustar a este marco primario de referencia (cfr. ВЕсK, 2005, pp. 38-51).

14 Cfr. Habermas, 1981, pp. 244-246. No obstante, en ese libro de 1976 encontramos una sugerente reflexión que rompe con ese enfoque estadocéntrico y que cuarenta años después adquiere incluso una mayor vigencia: «El desarrollo del mercado mundial, la internacionalización de capital y trabajo, también ha limitado hacia fuera el margen de acción del Estado nacional. [...] No es posible, empero, neutralizar las consecuencias del entreveramiento de las economías nacionales entre sí, por ejemplo: la influencia de las empresas multinacionales. Las exigencias de coordinación en el plano supranacional no resultan fáciles de satisfacer mientras los gobiernos se legitimen exclusivamente en virtud de decisiones nacionales, para lo cual hayan de reaccionar a desarrollos nacionales carentes en grado máximo de sintonía» (HABERMAS, 1981, p. 263).

15 A todo ello no fue ajeno la profunda transformación que experimento la arquitectura monetaria internacional: «El sistema de Bretton Woods, con su cambio de moneda fijo e instituciones como el Banco Mundial y el Fondo Monetario Internacional, representó un régimen económico internacional que permitió un equilibrio entre las políticas públicas nacionales y las reglas de un comercio mundial liberalizado. Después que este sistema fuera abandonado a principios de los años setenta, surgió un «liberalismo transnacional» completamente diferente» (HaBermas, 2000, p. 105).

16 Habermas, 2000, p. 105. Ello resulta evidente en el ámbito monetario, en donde, según nuestro autor, se aprecia una notable «limitación de la capacidad de actuación política de los Estados por parte de los "mercados"»(HABERMAS, 2016, p. 116).

17 Habermas, 2016, p. 118. 
sea posible el «keynesianismo en un solo país» ${ }^{18}$, ni tampoco el sostenimiento de las tradicionales funciones que los Estados asumían con el fin de cubrir las necesidades básicas de sus ciudadanos, tareas que al mismo tiempo les proporcionaban legitimidad. Sería poco, pues, lo que a los Estados les cabe hacer ya en el terreno económico:

«Los gobiernos nacionales, que apenas pueden influir con medidas macroeconómicas en el ciclo económico de sus, entre tanto, desnacionalizadas economías, deben limitarse, dadas las condiciones de la competencia económica global, a mejorar el atractivo de sus respectivas economías nacionales, es decir, a mejorar las condiciones de revalorización del capital» ${ }^{19}$.

Por lo demás, y ello posee la mayor relevancia desde la perspectiva normativa habermasiana, el desplazamiento del centro de decisión a los mercados no implica tan sólo pérdida de soberanía, sino también pérdida de democracia:

«El poder como mecanismo regulador de decisiones colectivas vinculantes opera con una lógica distinta a la que emplea el mercado. Por ejemplo, sólo el poder es susceptible de ser democratizado, no el dinero. Por lo tanto, las posibilidades de autocontrol democrático desaparecen per se cuando el mecanismo regulador de un determinado ámbito social se traslada de un medio de control a otro» ${ }^{20}$.

¿Qué le ha hecho a Habermas modificar su juicio sobre el sentido y el protagonismo de los Estados en nuestros días? La globalización, fundamentalmente. En la dinámica de diseminación del poder puesta en marcha por ella, Habermas ve un potente proceso capaz de modificar intensamente la esencia de la política ${ }^{21}$. Lo admite sin ambages: la tradicional visión nacional de los asuntos geopolíticos «está siendo puesta en cuestión por una serie de desarrollos que han suscitado un gran interés y que conocemos con el nombre de "globalización" " 22 . Habermas no llega a definir en sentido estricto este término ubicuo y escurridizo, pero no por ello deja de reconocer que esa noción, pese a sus insuficiencias, es, en cualquier caso, la que mejor da cuenta de un complejo conjunto de procesos de intensa transformación estructural registrados a lo largo del planeta en las últimas décadas. Y en este particular, son reconocibles las huellas que los análisis de sociólogos como Ulrich Beck, Anthony Giddens o Manuel Castells han dejado en sus planteamientos.

En las últimas décadas asistimos, según Ulrich Beck, a la puesta de largo de una «segunda modernidad», que como tal supone toda una ruptura con el molde con el que se fraguó la primera hornada. Si la primera modernidad estaba «basada en las sociedades Estados-nación, en las que las relaciones y redes

18 Cfr. Habermas, 2000, p. 106.

19 Habermas, 2000, p. 137. Desde una perspectiva igualitarista, centrada en mejorar la suerte de los más desfavorecidos, esto sería sin duda una claudicación inasumible.

20 Habermas, 2000, p. 105.

21 Cfr. Bohman, 2009, p. 291.

22 Habermas, 2000, p. 84. 
sociales y las comunidades se entienden en un sentido territorial $»^{23}$, ahora estarían surgiendo nuevos impulsos sociales que trastocan el marco político de referencia. Ello afecta, en particular, a la soberanía estatal, el axioma sobre el que pivotaba tradicionalmente el orden tanto interno como externo de la política. Los numerosos fenómenos de supranacionalidad normativa que regulan distintas esferas de acción, la liberalización de los flujos económicos que favorece la intervención de instituciones y actores económicos en las políticas internas, los grandes flujos migratorios o los fenómenos internos y globales de violencia, son factores, entre otros, que están debilitando las señas de la soberanía y reducen su potencial legitimador. La historia política de nuestro presente es una historia de soberanías amputadas. Siguiendo el surco dejado por autores como Beck, Habermas asume igualmente que la pretensión de soberanía que sustentaban los Estados - la pretensión de detentar un poder supremo e independiente - ha sido socavada por la emergencia de poderes transnacionales alternativos a la forma estatal tradicional, de modo que se ha ido desdibujando «la distinción entre política interior y exterior, distinción que es central en la constitución del Estado-nación ${ }^{24}$. A raíz de ese cuestionamiento de los Estados como únicos agentes legítimos aparece un nuevo escenario, el de nuestros días: un orden mundial inédito, que es precisamente aquello a lo que Habermas denomina constelación postnacional, cuya elucidación fue el tema central de un libro suyo con título homónimo publicado en 1998.

La cesión de soberanía ha ido tan lejos que referirse hoy a ella equivale básicamente a hablar de una quimera. No hay Estado que no dependa de un modo u otro de los demás y cuya soberanía no sea siempre limitada y/o compartida y ello ya representa en sí mismo una contradictio in terminis. No menos cierto es, sin embargo, que la soberanía estatal, entendida como poder absoluto y exclusivo del Estado en el marco territorial de su jurisdicción, como autonomía y autosuficiencia del aparato estatal, nunca llegó a darse plenamente, al menos en los términos cuasi teológicos - una versión secularizada, en realidad, del ilimitado poder divino- en los que fueron perfilados en los albores de la modernidad por autores como Jean Bodin y Thomas Hobbes o, en tiempos más recientes, por Carl Schmitt. Eso, no obstante, no era óbice para que la soberanía fungiera como el tipo ideal de autoridad suprema que regía y servía de referencia a lo largo del dilatado período de vigencia del llamado modelo westfaliano, un orden internacional basado precisamente en los Estados-nación soberanos ${ }^{25}$. Es precisamente a ese orden internacional históricamente en declive

23 BECK, 2002, p. 2.

24 Habermas, 2000, p. 95.

25 Con la Paz de Westfalia de 1648 se inició en Europa una dinámica histórica que, tras extenderse a los demás continentes a partir de las grandes revoluciones del siglo XVIII, condujo a la configuración de un orden internacional centrado en la figura de los Estados, a quienes se les atribuían competencias exclusivas de decisión tanto en el ámbito interno como en la representación externa. En correspondencia directa con estos presupuestos, «el imaginario jurídico se construyó en torno a la idea de la omnipotencia del legislador sobre 
a lo que Habermas denomina la constelación nacional, la configuración política que da por amortizada.

En Habermas, la superación del Estado nacional, que no su supresión ${ }^{26}$, se sustenta ciertamente en razones de corte normativo, razones estrechamente vinculadas con el universalismo que impregna y conforma la trama profunda de su teoría discursiva. Sin embargo, el peso de la argumentación lo pone sobre razones de carácter más bien sociológico estrechamente vinculadas a los procesos de globalización desplegados en las últimas décadas. En este asunto, su doble militancia como filósofo y como sociólogo de la que hace gala se escora claramente hacia esta última condición. Como se ha apuntado antes, contempla la globalización como un poderoso condicionante que limita significativamente el margen de maniobra de los Estados y por ello mismo considera que es preciso domeñarla en clave democrática. No oculta, en todo caso, su decepción con el curso emprendido por dicho proceso: a «la globalización económica deberían haber seguido una coordinación política a nivel mundial y la ulterior juridificación de las relaciones internacionales» ${ }^{27}$. Se debería estar aún a tiempo para remediar esta deriva, diría Habermas con una expresión de fuerte carga voluntarista. Más que resignación, en su propuesta de una «utopía realista» (por utilizar el oxímoron puesto en circulación por Rawls) se trasluce más bien el claro empeño de impugnar ese marcado sesgo neoliberal imperante en la gestión de la globalización que amenaza con disolver el cuerpo político en el mercado mundial.

\section{LA GOBERNANZA DE UN MUNDO INTERDEPENDIENTE}

Aunque quizás resulte prematuro hablar del fin de los Estados nacionales como consecuencia de su inadecuación a un mundo crecientemente globalizado, lo cierto es que se ha registrado una profunda transformación del papel que de ordinario se les atribuía y también, en cierto sentido, su paulatina deflación. Los Estados actuales (o, al menos, la mayor parte de

un territorio, de una organización jerárquica de la soberanía y de un único sistema de fuentes del derecho válido al interior de las fronteras de cada Estado concreto» (MATTEI, 2013, pp. 28-29). En realidad, este ideal de concentración del poder fue puesto en práctica en pocos lugares de manera completamente coherente, pero alcanzó una indudable supremacía en el plano teórico.

26 Cfr. Habermas, 1999, p. 105. Aunque Habermas toma cumplida nota de que los Estados nacionales en la era de la globalización adolecen de una considerable merma de soberanía, no llega a preconizar su final. Marcaría así distancia con Carl Schmitt, un autor cuya sombra siempre le persigue y que, como se recordará, ya en 1932 (año de la segunda edición de su El concepto de lo político, que es la versión que ha devenido en canónica) daba por ineluctable la obsolescencia de la forma estatal: «La época de la estatalidad toca ahora a su fin. [...] el Estado como modelo de la unidad política, el Estado como portador del más asombroso de todos los monopolios, el de la decisión política, [...] ha sido destronado» (Sснмiтt, 2002, p. 40).

27 Habermas, 2012, pp. 100-101. 
ellos) se han convertido en unos actores más entre los muchos que proliferan en el escenario global y con frecuencia ni siquiera alcanzan la categoría de genuinos global players. Se ha producido un vaciamiento de sus poderes de control efectivo y de sus principios constitutivos (territorialidad y soberanía). No tienen la escala óptima ni constituyen ya el marco de acción adecuado para la resolución de los problemas colectivos más acuciantes. Son demasiado grandes para poder suscitar la lealtad y la legitimidad que se precisan para poner en marcha el ideal democrático y son demasiados pequeños para afrontar con solvencia los graves problemas del planeta que, desde los movimientos globales de capitales hasta el calentamiento global, amenazan el bienestar de las personas. Si este diagnóstico es certero, cabe preguntarse por la forma política que reemplazará a la forma Estado, esto es, por la nueva configuración postestatal que adoptará lo político en una constelación de fuerzas en la que los Estados nacionales ya no representan forzosamente el escenario decisivo.

La creciente integración económica a nivel transnacional contrasta con el elevado grado de fragmentación política que caracteriza a la sociedad mundial, una fragmentación que se traduce en una exigua capacidad para la cooperación y la coordinación interestatal ${ }^{28}$. A la manifiesta inoperancia del marco estrictamente estatal en asuntos clave, Habermas añade otra evidencia quizás aún más alarmante: «En el mundo que aún sigue dominado por los Estados nacionales todavía no existe un sistema capaz de actuar políticamente que pueda asumir la "responsabilidad global" exigida desde el punto de vista moral» ${ }^{29}$. Este inventario de carencias le sirve a nuestro autor como punto de partida para señalar los lineamientos básicos de todo un ambicioso plan consistente en la institucionalización de un orden global dotado de la competencia necesaria para afrontar los nuevos retos.

Los Estados soberanos, carentes de la autosuficiencia de la que alardeaban, se encuentran abocados, quieran o no, a la coordinación y a la responsabilidad compartida: «Las sociedades actuales, constituidas en torno al Estado-nación, pero rebasadas en sus capacidades por las distintas hornadas de desnacionalización, no tienen más remedio que "abrirse" a una sociedad mundial que se les ha impuesto a través de la economía ${ }^{30}$. Es en ese contexto donde se presenta como opciones dignas de consideración la instauración bien de una auténtica agencia política mundial bien de múltiples agencias globales temáticas o sectoriales. Sea de un modo o de otro, la configuración de un espacio supraestatal de acción no sería sino la requerida respuesta ante la percepción de que los riesgos y las diversas amenazas globales sobrepasan la capacidad de acción de los Estados.

28 Cfr. Habermas, 2016, p. 118

29 Habermas, 2001, p. 205.

30 Habermas, 2000, p. 85. 
Yendo más allá de la descripción de lo existente, y con el fin de tratar de superar la manifiesta falta de escala de los Estados nacionales ${ }^{31}$, Habermas adopta un enfoque propositivo con un sesgo nítidamente cosmopolita. Así, además de preconizar la atribución de agencia jurídico-política a todos los habitantes de planeta en la esfera internacional, acaba perfilando una arquitectura institucional encaminada a alcanzar un orden de factura tendencialmente democrática en el ámbito global ${ }^{32}$. El reto estriba en cómo encaminarse hacia «una política interior mundial sin gobierno mundial $»^{33}$. Para este empeño, Habermas encuentra una fuente de inspiración en el pensamiento de Kant, al que sigue, aunque intentando no quedar preso en sus intricadas redes teóricas y conceptuales para poder así ajustarse mejor a las actuales circunstancias históricas. Retoma en concreto el proyecto formulado en La paz perpetua, un opúsculo que desde que Kant lo publicara a finales del siglo XVIII no ha dejado de ejercer una notable influencia tanto académica como extra-académicamente. Situándose en esa prestigiosa senda kantiana, Habermas aboga por transitar desde un derecho internacional centrado en los Estados nacionales hacia un derecho de corte cosmopolita, entendiendo como tal un derecho en que no sólo los Estados sino también los individuos sean sujetos de derecho ${ }^{34}$. La juridificación de las relaciones de poder existentes en la política mundial, esto es, el sometimiento de los poderes globales, regionales y nacionales al derecho, su reconducción hacia canales jurídicos, formaría asimismo parte esencial de la vía propuesta para la regulación pacífica de los litigios y el aseguramiento de la libertad de los individuos.

La idea de un marco regulatorio mundial y una correspondiente autoridad supranacional creíble no ha de concretarse necesariamente en la creación de

31 La mayoría de los Estados, por no decir todos, no sólo carecen de la escala adecuada, sino que en los asuntos más relevantes suelen ir por detrás de los acontecimientos y apenas son capaces de poner en marcha medidas pro-activas: «Los Estados no dominan ni ordenan, sino que reaccionan a los movimientos y a los imperativos del capital así como a otros fenómenos globales, desde el cambio climático hasta las redes del terrorismo internacional» (BRown, 2015, p. 100).

32 Al contraponerlo a "soberanista», el sentido del término "cosmopolita» adquiere un perfil mucho más nítido. Mientras que los primeros se resisten a aceptar la universalidad de los derechos humanos o el derecho de injerencia en los asuntos internos de los Estados, e insisten en mantener la inviolabilidad de las fronteras, los «cosmopolitas» defenderían justo lo opuesto: además de argumentar a favor de la capacidad de agencia política de los individuos en la esfera internacional, insisten en depositar de manera más o menos paulatina competencias en instituciones supraestatales y en limitar la soberanía de los Estados.

33 Habermas, 2000, p. 136. La envergadura del objetivo propuesto por Habermas es considerable, pues «no puede entenderse como una propuesta de mínimos, sino que contiene una radical transformación del propio sentido del orden internacional hacia el derecho cosmopolita» (GARCía PASCUAL, 2015, p. 189).

34 Cfr. Habermas, 2006a, pp. 121-124. Un derecho cosmopolita regularía no sólo las relaciones entre los distintos Estados, sino también entre todos los seres humanos, de modo que éstos fueran, además de ciudadanos de sus respectivos Estados, ciudadanos también de una entidad supraestatal de alcance global y, por tanto, agentes activos en la esfera internacional. 
un centro gubernamental unificado de alcance planetario que reemplace a los Estados existentes. Una única estructura política análoga a los Estados nacionales trasladada al ámbito planetario podría constituir un mal aún mayor que el propio desorden existente. Sería «un modelo equivocado» ${ }^{35}$, pues más que un gigante benefactor, el Estado mundial podría acabar resultando un ogro tiránico y totalitario, un Leviatán carente de bridas y sin posible rival. En la apreciación de este riesgo Habermas coincidiría una vez más con Kant:

«En último término, lo que inquieta a Kant es la alternativa entre el dominio mundial de un único gobierno monopolizador de la violencia y el sistema existente de múltiples Estados soberanos. Con la concepción sustitutoria de una «asociación de naciones» busca una salida a esa alternativa ${ }^{36}$.

Los Estados no serían eliminados, pero dejarían de ser los centros últimos de decisión. Seguirían poseyendo la condición de interlocutores imprescindibles, y a veces podrán ser global players relevantes, pero ya no serían los únicos, ya que compartirían protagonismo con agentes transnacionales no estatales y con instituciones supraestatales. Esta nueva comprensión del papel de los Estados encuentra su traducción institucional en una estructura multinivel y descentralizada que a su vez guarda correspondencia con la multiplicidad de escalas existentes en la esfera global, de modo que los diversos poderes y niveles mantengan un juego de restricciones mutuas. El reto, al menos desde una clave democrática, sería, pues, de una formidable complejidad, ya que, como el propio Habermas reconoce, quienes pugnen por ello se verán «obligados a desarrollar al menos modelos para un arreglo institucional que pueda garantizar una legitimación democrática a las nuevas formas de gobernación de los asuntos en espacios que carecen de fronteras» ${ }^{37}$. Mucho es, por tanto, lo que falta por pensar acerca de cómo articular la democracia con la gobernanza en un mundo globalizado.

Aunque Habermas recurre en raras ocasiones al término «gobernanza» en su literalidad, emplea expresiones que recogen su sentido básico. Se refiere, por ejemplo, a la construcción de un sistema de negociación transnacional exento de formas jurídicas ${ }^{38}$, una idea que guarda una estrecha correspondencia con el sentido de esa noción. La "gobernanza» adolece —como término líquido que es- de un considerable grado de indeterminación semántica, algo que «lo habilita para todo tipo de eufemismos» y que a la vez lo dota del «aura de lo oportuno y lo moderno» ${ }^{39}$. En su influyente acepción neoliberal, el término

35 Habermas 2006a, p. 131.

36 Habermas 2006a, p. 126. Pese a la rotundidad con la que Habermas rechaza la conveniencia de instaurar un Estado mundial en el citado texto, algunos de los primeros escritos sobre la cuestión (cfr. HABERMAS, 1999) dieron pie a que su propósito fuera interpretado en sentido contrario y se convirtiera en objeto de aceradas críticas por autores autoclasificados como realistas (cfr. ZoLo, 2005, pp. 57-58).

37 Habermas, 2009, p. 109.

38 HABERMAS, 2012, pp. 81 y 99.

39 Cfr. OfFe, 2009, pp. 550-551.. 
sugiere la voluntad de poner en marcha un proceso de «desdemocratización de la democracia», de modo que puede ser concebida como «una forma de estatismo sin Estado $»^{40}$ y como expresión de miedo o de alergia a la política. Ambas apreciaciones tienen pleno sentido en el ámbito interno de aquellos Estados regidos hasta ahora por estrictos criterios de democracia representativa. Introducir ahí elementos de gobernanza constituye un indudable retroceso, pero no así en el ámbito internacional donde la anarquía ha campado hasta ahora. Su uso resulta adecuado para designar formas de coordinación de la acción colectiva distintas a las típicamente gubernamentales, que es precisamente lo que pretende Habermas.

Por «gobernanza» puede entenderse un estilo de gobierno que promueve relaciones en red, no jerárquicas, sino horizontales, entre centros institucionales públicos y actores colectivos de diverso nivel de actuación (local, estatal y/o internacional) y que cuenta con el principio de subsidiariedad en lugar del de centralización para el manejo de problemas comunes. Es esclarecedora en este sentido la definición de gobernanza propuesta por Alessandro Ferrara: «la coordinación y la regulación de la acción política en ausencia de la capacidad de imponer sanciones en caso de incumplimiento ${ }^{41}$. Y sería precisamente en la esfera global, en donde como es sabido no se dispone de una agencia política que cuente con el monopolio legítimo de la violencia, donde tal idea tendría un mayor valor heurístico.

Gobernanza global no es sinónimo de gobierno mundial ni de control directo de los procesos globales mediante un instrumento político análogo al Estado ${ }^{42}$. Existen otras vías posibles para dar cuenta de la estructura reticular que conforma la política mundial (de las múltiples interacciones de los diversos actores en juego) y entre ellas se encontraría precisamente el proyecto habermasiano de juridificación de la esfera internacional, que propugna «una domesticación del poder mediante la distribución institucional y la regulación procedimental de las relaciones de poder existente» ${ }^{43}$.

A la hora de pensar en cómo implementar su proyecto, Habermas posee una ventaja epistémica no menor con respecto a Kant, a saber: la de haber aprendido de las experiencias históricas desarrolladas en los últimos doscientos años. Con el fin de alterar sustancialmente las trazas westfalianas aún perceptibles

40 Cfr. Balibar, 2013, pp. 12 y 43.

41 Ferrara, 2014, p. 323. Según este mismo autor, el núcleo conceptual central de dicha noción "puede entenderse de un modo general como la coordinación de complejas redes de acción durante largos períodos de tiempo en ausencia de una estructura de autoridad dotada de la capacidad de imponer sanciones en última instancia respaldadas por el uso de la fuerza» (ibidem). Las únicas sanciones, si las hay, sólo podrán ser indirectas, propias de un soft law: una mayor probabilidad de experimentar las desventajas de no actuar de manera coordinada y, en el caso más extremo, la pena del aislamiento político dentro de la comunidad internacional.

42 Cfr. INNERARITY, 2013.

43 Habermas, $2006 a$, p. 135. 
en la esfera internacional ${ }^{44}$ y poder afrontar airosamente el reto de garantizar la obligatoriedad de la legislación internacional sin incurrir en despotismo. Habermas siempre tiene en mente el singular caso de la Unión Europea. En el seno de esa novedosa institución política (al menos, en términos históricos y comparados), «los Estados miembros tienen todavía el monopolio del poder y, no obstante, aplican, más o menos sin quejarse, el derecho aprobado en el plano supranacional» ${ }^{45}$. La Unión ha puesto en marcha procesos inéditos en muchos aspectos, sobre todo en la medida en que establece un marco cooperativo de estrecha interacción basado tanto en una jurisdicción expansiva como en el ejercicio de una autoridad difusa que permite realizar cosas sin tener en ocasiones la competencia expresa para ordenarlas. La complejidad de este entramado, puesto a prueba en las muy adversas circunstancias de la última crisis económica, a duras penas pueden ser captada, sin embargo, con el lema desdeñoso de una «Europa postdemocrática» acuñado por el propio Habermas para criticar la falta legitimidad de las rigurosas decisiones tecnocráticas impuestas a algunos de los países miembros ${ }^{46}$. Pese a la implacabilidad de este juicio, nuestro autor no deja de apreciar en la Unión Europea un valioso modelo para la sociedad mundial constituida políticamente, un modelo al menos en dos relevantes aspectos: a) en lo que respecta a la subordinación de los Estados a un derecho común supranacional; y b) en lo referente a la configuración de un doble sujeto soberano, los Estados nacionales y los ciudadanos ${ }^{47}$. Subsiste no obstante una diferencia cardinal entre el proyecto europeo y el cosmopolita: mientras que la Unión Europea no deja de ser una unidad política particular y tiene, por tanto, que desarrollar una política interior y exterior, la comunidad mundial carecería por definición de política exterior.

Aunque Habermas tiene muy presente la experiencia europea a la hora de esbozar su propuesta de un sistema mundial multinivel, busca fórmulas con un perfil aún más descentralizado. Por ello, acaba esbozando una configuración política que, en sintonía con la preocupación por preservar la pluralidad nacional de las sociedades humanas, se distinguiría por la multiplicidad de actores y procesos decisorios, y en el que coexistirían elementos intergubernamentales y supraestatales, además de múltiples jurisdicciones territoriales. Se trata de un modelo político que se estructuraría en tres niveles: en el plano nacional, en el supranacional y en el transnacional ${ }^{48}$. Diferentes niveles cuya complementariedad tendría como objetivo la articulación de una política mundial sin gobierno

44 Como señala Brown (2015, p. 97), en el período postwestfaliano en el que estamos insertos se superan determinados elementos de la fase anterior al tiempo que se mantienen (en el sentido del aufheben hegeliano), de tal modo que «hay más bien una dispersión de elementos de soberanía política que una transferencia in toto de la misma». De hecho, aunque con algunas salvedades, aún sigue vigente el principio de no injerencia en los asuntos internos y las fronteras estatales siguen mereciendo la máxima protección internacional.

45 Habermas, 2012, p. 103.

46 Cfr. Habermas, 2016, pp. 114-129.

47 Cfr. Habermas, 2012, pp. 78-79.

48 Cfr. Habermas, 2006a. 
mundial y romper así con la analogía postulada entre la constitución política nacional y la mundial.

El Estado territorial soberano sería el actor principal del primer nivel propuesto, mientras las Naciones Unidas serían la institución prototípica del segundo, aunque corrigiendo las deficiencias que históricamente arrastra. En el tercer nivel, quizás el más novedoso y menos estructurado, serían protagonistas los numerosos global players no estatales que han ido apareciendo en los últimos años. La pujanza de los movimientos sociales transnacionales y de las organizaciones no gubernamentales que configuran este nivel sería decisiva no sólo para activar las conciencias, sino también para poder presionar a los Estados y forzarlos a nuevos acuerdos que favorezcan una mayor integración, sobre todo en materia de derechos humanos, mantenimiento de la paz y protección integral del medio ambiente ${ }^{49}$.

En el segundo nivel, Habermas propone relevantes reformas dirigidas a fortalecer el papel de los sistemas intergubernamentales de negociación, en especial, el de la ONU, para lo que sería preciso profundizar tanto en su cosmopolitización como en su democratización, de modo tal que se presente simultáneamente como "una comunidad de Estados y de ciudadanos». Las innovaciones deberían llevarse a cabo tanto en el ámbito legislativo (Asamblea General, que debería configurarse como una suerte de parlamento mundial) como en el ejecutivo (Consejo de Seguridad, tanto en lo referente a su composición como al procedimiento de decisión ordinario) y en el judicial (Tribunales Internacionales) con el fin de reforzar su legitimidad. Habermas mantiene una posición bastante realista en cuanto a las posibilidades de transformación del orden internacional, pues considera que dado que las Naciones Unidas están limitadas «a la cuestión de garantizar un orden elemental, de la más ambiciosa reforma de las actuales instituciones no podría surgir nunca un gobierno mundial» ${ }^{50}$. Su propósito no sería sino «reforzar un proceso, que ya está en marcha, de constitucionalismo supranacional $»^{51}$. La ONU debería ser complementada además mediante la creación y/o potenciación de procesos de integración regional o continental (como los protagonizados por MERCOSUR, NAFTA, ASEAN o la Unión Europea). Estas reformas tendrían que concretarse de tal manera que dieran juego reconocido a los nuevos actores que conforman el tercer nivel y que actuarían como plataformas de intermediación entre los otros dos niveles.

A favor de una gobernanza global, Habermas no sólo presenta argumentos funcionales, sino también razones vinculadas a la noción de justicia social. Esa forma de gobernanza podría ser un instrumento útil para contrarrestar el progresivo «desmontaje del Estado social $»^{52}$, la creciente «desregulación de la política social», consecuencia al menos en parte de la insuficiente capacidad

49 Cfr. Habermas, 1999, p. 105; y Habermas, 2000, 138-142.

50 Habermas, 2000, p.139.

51 García Pascual, 2015, p. 183.

52 Cfr. Habermas, 2000, p. 104. 
recaudatoria de un Estado nacional desbordado por la globalización económica. Se pone así en marcha una poderosa dinámica que actúa en contra de la integración de los más desfavorecidos y provoca una crisis de la solidaridad que a la larga destruye los fundamentos sobre los que se asienta toda sociedad demo-liberal. De esa constatación — de la evidencia de que la globalización de la economía destruye una constelación histórica que hizo posible los compromisos del Estado social ${ }^{53}$ - procede la insistencia de Habermas «en que la justicia social y los derechos sociales ya sólo van siendo viables en el marco de una política mundial coordinada y regida por los valores universalistas hasta ahora propios del Estado social de Derecho ${ }^{54}$. Sería ahora el momento de llevar a una escala más elevada los presupuestos que animaban a esa forma de Estado a fin de garantizar su realización efectiva.

La extensión de la conciencia cosmopolita en nuestros días responde probablemente no tanto al progreso de los sentimientos morales - aquello que nos llevaría empatizar con el sufrimiento de todos los miembros de la humanidad y/o nos movería a realizar acciones altruistas sin pensar en las fronteras- como a razones prudenciales y/o estratégicas mucho más prosaicas. Y entre esos motivos se encontraría la urgencia de afrontar unidos riesgos comunes que desbordan las capacidades de los distintos países por separado o, dicho con palabras de Habermas, «de responder a las necesidades de conducción y regulación resultantes de la interdependencia, cada mayor, de una sociedad mundial» ${ }^{55}$. La conciencia compartida de riesgos y necesidades comunes adquiere, como diría Beck, una función integradora. El autointerés - que como ya había señalado Hobbes sería una poderosa razón para dar el paso desde el estado de naturaleza a la sociedad política - sería también el móvil que impulsaría a los Estados particulares a superar la perspectiva estrictamente nacional y cooperar con los demás los Estados en clave cosmopolita. Planteado el asunto desde este enfoque más pragmático, se debilitaría enormemente la reiterada acusación de representación fantástica o extravagante que reciben quienes como Habermas defienden la conveniencia de implementar un proyecto cosmopolita. La esfera internacional ha dejado de ser de facto un entorno enteramente anárquico y se va vislumbrando una cierta tendencia a la concertación cooperativa o la acción multilateral coordinada, una forma de actuación que, en detrimento de las añejas ideas de soberanía y autosuficiencia, se asentaría en la mencionada noción de interdependencia ${ }^{56}$.

53 Cfr. Habermas, 2000, pp. 83-84.

54 García Amado, 2007, p. 363. Habermas tiene motivos de justicia para buscar formas de gobernanza global que garantice el mantenimiento del Estado de bienestar, pero sin embargo no atribuye ninguna función distributiva a la instancias supranacionales de coordinación. Éstas sólo tienen como misión el mantenimiento de la paz y la garantía de los derechos humanos. Habermas no se encuentra, por tanto, entre los instigadores de la justicia (distributiva) global.

55 Habermas, 2009, p. 107.

56 Cfr. INNERARITY, 2013. 
Dar respuesta a las demandas de una mayor coordinación y cooperación es un paso que en principio les correspondería dar a los distintos poderes que actúan globalmente, que «deben estar dispuestos a ampliar su perspectiva del «interés nacional» hasta alcanzar el punto de vista de una global governance. No obstante, este cambio de perspectiva, desde las "relaciones internacionales» hasta una política interior mundial», y en esto insiste Habermas, "no hay que esperarla de los gobiernos a menos que los pueblos premien este cambio de conciencia ${ }^{57}$. El impulso ciudadano sería, pues, a la postre, indispensable y decisivo.

\section{GoBERNANZA GLOBAL Y DEMOCRACIA}

En el sistema westfaliano, la soberanía nacional tenía validez como mínimo en un sentido ideal, esto es, como principio regulativo que delimita procesos políticos y sociales y que define un horizonte de expectativas para los diferentes actores. Y fue en ese marco nacional, como Habermas no olvida señalar, en donde «el proceso democrático, en mayor o menor medida, pudo adoptar una convincente forma institucional ${ }^{58}$. Habermas no oculta la dificultad de que la dinámica democrática encuentre su lugar en marcos de acción política de un formato mucho mayor, pero no por ello capitula en su propósito de regenerar en el nivel supranacional esa fuerza de la legislación democrática reguladora del mercado que una vez estuvo concentrada en los Estados nacionales ${ }^{59}$. Los efectos derivados de la aparición de ese nuevo escenario geopolítico que él mismo denomina constelación postnacional, una compleja constelación de poderes heterogéneos, son no obstante perceptibles de una manera muy directa en la comprensión y funcionamiento de la democracia, cuyos fundamentos e instrumentos básicos son puestos en cuestión:

«Porque si el Estado soberano ya no se concibe como algo indivisible sino como algo compartido con agencias internacionales; y si las fronteras territoriales y políticas son cada vez más difusas y permeables, los principios fundamentales de la democracia liberal, es decir, el autogobierno, el demos, el consenso, la representación y la soberanía popular se vuelven problemáticos ${ }^{60}$.

En este marco, la transferencia de poder estatal hacia las instituciones supranacionales en aras de la eficacia genera indefectiblemente quebranto en la participación ciudadana y, a la postre, un déficit de legitimidad. Estos

57 Habermas, 2000, p. 145.

58 HABERMAS, 2000, p. 83.

59 Cfr. Habermas, 2016, p. 119.

60 Habermas, 2000, p. 84. Estas palabras son de Anthony McGrew y Habermas las hace suyas. 
«agujeros de legitimidad», como los llama Habermas ${ }^{61}$, se tornan más visibles en la medida en que decisiones relevantes se sustraen a las exigencias de los controles democráticos. Desde una comprensión débil de la democracia sería, sin duda, mucho más sencillo plantear la posible plasmación de la democracia a nivel planetario, que es como proceden, por ejemplo, David Held y Daniele Archibugi, por un lado, u Otfried Höffe, por otro ${ }^{62}$. Pero Habermas sostiene una versión exigente de democracia, la democracia deliberativa. No basta con que la delegación de poderes a una institución supraestatal consiga recabar en un momento dado un asentimiento explícito y generalizado. $\mathrm{Si}$ «no queremos declarar con todo descaro que la democracia es un mero decorado" (Habermas, 2015), los ciudadanos tendrán que disponer de mecanismos eficaces para ejercer control e influencia directa y permanente también a ese nivel. La autodeterminación del pueblo forma parte del núcleo duro normativo de la idea habermasiana de democracia. En ella, la intervención del pueblo y los controles democráticos son criterios vinculantes, esto es, condiciones necesarias, aunque no suficientes, de un régimen que se precie de democrático. Sin embargo, sin contar con un demos mundial, con un nivel mínimo de integración y articulación interna, estas exigencias son difícilmente trasladables al nivel global. Tras constatar que no está en el horizonte la pronta superación de esta carencia, Habermas acaba por reconocer lo poco factible que es la democracia a escala planetaria. Reconocer la imposibilidad de una democracia cosmopolita en sentido estricto no implica, al menos en el caso de nuestro autor, tener que renunciar a la introducción de canales participativos y deliberativos en el ámbito global que induzcan la progresiva emergencia de un sentimiento de pertenencia a una ciudadanía común. Lejos de permanecer apegado a la realidad, se empeñaría, pues, en ofrecer alternativas constructivas.

Encontrar alguna salida airosa a ese señalado dilema entre eficacia y legitimidad es algo que ha preocupado a Habermas desde que en 1995 comenzó a ocuparse de la organización política de la esfera global, aunque muy probablemente aún no haya acabado de dar con una solución convincente. Ésta sería la cuestión que persiguió no sólo en aquel largo artículo de 1998 titulado «La constelación postnacional y el futuro de la democracia», sino también en muchas de sus intervenciones posteriores, incluido su último libro: En la espiral de la tecnockracia (2013), en donde alerta sobre la sustitución de la participación y la representación ciudadana por formas autoritarias de gobierno tecnocrático tanto en el ámbito intraestatal como, sobre todo, en la esfera supranacional ${ }^{63}$. Lo prioritario, según nuestro autor, sería plantar cara a la tendencia a la despolitización y desdemocratización cada vez más palpable a todos los niveles. Ante esta situación, Habermas no duda en el objetivo: «Sólo podemos hacer frente de forma racional a los desafíos de la globalización si

61 Habermas, 2000, p. 96.

62 Cfr. Held y ARchibugi, 1995; y HöFfe, 1999.

63 Cfr. Habermas, 2000, pp. 81-146; y Habermas, 2016. 
logramos desarrollar dentro de la constelación postnacional nuevas formas de autocontrol democrático de la sociedad ${ }^{64}$. Para ello, como señala Wolfgang Streeck, cuyas palabras Habermas hace suyas, sería preciso:

«construir instituciones con las que se pueda poner nuevamente los mercados bajo control social: mercados de trabajo, que dejen espacio para la vida social; mercados de bienes, que no destruyan la naturaleza; mercados de créditos, que no devengan producción de masas de promesas incumplibles ${ }^{65}$.

Algo diferente es que nuestro autor sepa precisar cuáles serían las mediaciones requeridas para lograr esas ambiciosas metas, cuya complejidad no se le oculta, obviamente. Partiendo de la certeza de que las instituciones democráticas operativas a escala nacional no son trasladables sin más a escala global, se plantea la cuestión de cómo es posible sortear el riesgo más que latente de déficit democrático que sobrevuela sobre las instituciones supranacionales sin incurrir en los vicios del elitismo o de la tecnocracia. Tras ofrecer varias adaptaciones del proyecto cosmopolita kantiano a la realidad contemporánea, el camino que finalmente encuentra Habermas, y que es el que se plasma en su tercera y última versión ${ }^{66}$, consistiría en la configuración —que ya fue esbozada en la sección anterior de este artículo- de una sociedad mundial organizada en múltiples niveles, con una diferenciación funcional entre los mismos y la adjudicación a cada nivel de un grado de exigencia democrática diferente. El objetivo de la constitucionalización de la sociedad cosmopolita, su juridificación, no es otro que el de delimitar el poder entre los distintos niveles. En correspondencia, la carga de legitimación también estaría repartida entre esos niveles. En el nivel nacional, la legitimidad sería entera y exigentemente democrática. En el plano transnacional, la legitimidad, por el contrario, sería una cuestión de política y negociación entre los distintos actores. En el plano supranacional, cuya agenda es sumamente modesta, restringida al aseguramiento de la paz y la protección de los derechos humanos, de los que todos los individuos son titulares, las tomas de decisiones han de seguir procedimientos eminentemente jurídicos y de este modo obtendrían la legitimidad requerida ${ }^{67}$. Si bien cada nivel

64 HaBermas, 2000, p. 105.

65 Habermas, 2016 , p. 117.

66 En su primera versión, Habermas abogaba por una democracia cosmopolita; tras advertir serias dificultades, pasó a abogar por un enfoque en el que la negociación entre las partes primaba sobre los procesos democráticos. En la tercera versión, el objetivo no es otro que la constitucionalización del derecho internacional sin democracia. Al respecto, cfr. BOHMAN, 2009.

67 Habermas auspicia, en la senda trazada a mediados del siglo pasado por HANS KELSEN (2003[1944]), la creación de una jurisdicción universal y obligatoria dirigida a enjuiciar graves violaciones de derechos humanos. Esta vía kelseniana, la paz por medio del derecho, que Habermas hace suya, contrasta abiertamente con la propuesta por Hugo Grocio, la guerra por medio del derecho (cfr. PEÑA, 2014), que sería, en definitiva, la seguida por Carl Schmitt. No en vano para este jurista germano la política queda reducida en gran parte a una cuestión de mera fuerza, a una confrontación sin reglas. La guerra, para Schmitt, no sería sino un instrumento legítimo de la política exterior. 
genera su propia fuente de legitimidad, no lo hace de manera autosuficiente. Por el contrario, han de complementarse mutuamente, lo que a su vez exige un mayor esfuerzo de coordinación entre los niveles.

La emergencia de una sociedad política mundial multinivel altera radicalmente la compresión tradicional del campo de juego de la democracia. De entrada, multiplica sustancialmente el número de actores a tener en cuenta y con ello las posibilidades de llegar a acuerdos. Su operatividad real dependerá, no obstante, de que se logre no sólo desmantelar o superar un presupuesto básico del modelo westfaliano - que los únicos sujetos acreditados del derecho internacional son los Estados- sino también avanzar en el efectivo empoderamiento democrático de los individuos como agentes activos en la esfera pública global. Una genuina perspectiva cosmopolita de la democracia apunta, pues, hacia una configuración postwestfaliana del orden internacional. Con ello, Habermas ha dejado planteado tan sólo el camino a seguir, la llegada efectiva a esa promisoria meta no es más que una cuestión abierta puesta en manos de los ciudadanos.

\section{Bibliografía}

Nota: Cuando hay traducción al castellano sólo se indica ésta. Entre corchetes, detrás del título de la obra, se señala el año de su primera edición en la lengua original.

Balibar, É. (2013), Ciudadanía, Buenos Aires, Adriana Hidalgo.

BECK, U. (2002), La sociedad del riesgo global [1999], Madrid, Siglo XXI.

- (2005), La mirada cosmopolita o la guerra es la paz [2004], Barcelona, Paidós.

BenhaBIB, S. (2005), El derecho de los otros [2004], Barcelona, Gedisa.

Bонмал, J. (2009), «Völkerrechtsverfassung und Politik», en Hauke Brunkhorst et al., eds., Habermas-Handbuch, Stuttgart, Metzler, 291-300.

Brown, W. (2015), Estados amurallados, soberanía en declive [2010], Barcelona, Herder.

CoHEN, J. L. (2009), «Völkerrechtsverfassung», en Hauke Brunkhorst et al., eds., Habermas-Handbuch, Stuttgart, Metzler, 87-94.

FerRaRA, A. (2014), El horizonte democrático [2013], Barcelona, Herder.

Fraser, N. (2008), Escalas de justicia [2008], Barcelona, Herder.

García Amado, J. A. (2007), «Habermas, los Estados y la sociedad mundial», en Revista de Ciencias Sociales, $\mathrm{n}^{\circ}$ 52, 347-378.

García Pascual, C. (2015), Norma mundi. La lucha por el derecho internacional, Madrid, Trotta.

Habermas, J. (1973), «Concepto de participación política» [1958], en W. Abendroth et al., Capital monopolista y sociedad autoritaria, Barcelona, Fontanella, 15-61.

- (1981), La reconstrucción del materialismo histórico [1976], Madrid, Taurus.

- (1989), Identidades nacionales y postnacionales, Madrid, Tecnos.

- (1998), Facticidad y validez [1992], Madrid, Trotta.

- (1999), La inclusión del otro [1996], Barcelona, Paidós.

- (2000), La constelación posnacional [1998], Barcelona, Paidós.

- (2001), Israel o Atenas, Madrid, Trotta. 
- (2006a), «El proyecto kantiano y el Occidente escindido», en idem, El Occidente escindido [2004], Madrid, Trotta, 113-187.

- (2006b), «Espacio público y esfera pública política. Raíces biográficas de dos motivos intelectuales», en idem, Entre naturalismo y religión [2005], Barcelona, Paidós, 19-30

- (2006c), «¿Una constitución política para una sociedad mundial pluralista?», en idem, Entre naturalismo y religión [2005], Barcelona, Paidós, 315-355.

- (2009), «Constitucionalización del derecho internacional y problemas de legitimación de una sociedad mundial constitucionalizada», en idem, ;Ay, Europa! [2008], Madrid, Trotta, 107-126.

- (2012); «La crisis de la Unión Europea a la luz de una constitucionalización del derecho internacional» [2011], en idem, La Constitución de Europa, Madrid, Trotta, 39-91.

- (2015), «El gobierno de los banqueros», en El País, (accesible online: http://internacional.elpais.com/internacional/2015/06/26/actualidad/1435340365_023707.html).

- (2016), En la espiral de la tecnocracia [2013], Madrid, Trotta.

Held, D. y Archibugi, D. (1995), Cosmopolitan Democracy, Cambridge, Polity.

Höffe, O. (1999), Demokratie im Zeitalter der Globalisierung, Múnich, Beck.

Iglesia Vila, M. (2011), en «La pobreza extrema en tiempos de crisis», en Gascón, M. et al., Cuestiones actual de derecho sanitario y bioética, Valencia, Tirant lo Blanch, 1151-1194.

InNERARITY, D. (2013), Un mundo de todos y de nadie, Barcelona, Paidós.

KANT, I. (1985), La paz perpetua [1795], Madrid, Tecnos.

Kervégan, J.-F. (2013), ¿Qué hacemos con Carl Schmitt? [2011], Madrid, Escolar y Mayo. Mattei, U. (2013), Bienes comunes. Un manifiesto, Madrid, Trotta.

Offe, C. [2009], «Governanze: An 'Empty Signifier'?», en Constellations, vol 16, 550-562.

PeÑA, J. (2014), «Hugo Grocio, la guerra por medio del derecho», en Araucaria, $\mathrm{n}^{\circ} 32$, 69-92

Sснмітт, C. (2002), El concepto de lo político [1932], Madrid, Alianza.

Velasco, J. C. (1997), «Ayer y hoy del cosmopolitismo kantiano«, en Isegoría, nº 16, 91-117.

- (2001), «Los contextos del patriotismo constitucional», en Cuadernos de Alzate, $\mathrm{n}^{\circ} 24$, pp. 63-78

- (2013), Habermas. El uso público de la razón, Madrid, Alianza.

Zolo, D. (2005), Los señores de la paz. Una crítica del globalismo jurídico [1998], Dykinson, Madrid.

Instituto de Filosofía del CSIC (Madrid)

jc.velasco@csic.es

Juan Carlos Velasco

[Artículo aprobado para publicación en diciembre de 2015] 